\title{
Feasibility study of pumping cycle kite power system implication in Scotland UK
}

\author{
Zhihui Ye, Harry Lawner, Issa Chaer, Marcus Ross* \\ School of The Built Environment and Architecture, London South Bank University, 103 Borough Road, London, UK, SE1 OAA
}

\begin{abstract}
To meet the worldwide requirements of carbon emission reduction, the European Council set a target for $15 \%$ of final energy consumption in the UK to come from renewable energy by 2020. In the UK, the Climate Change Act (2008) set a target for the reduction of $80 \%$ of carbon emissions by 2050 . The biggest renewable energy sources in the UK are bioenergy, wind, solar and hydro. The UK is located in a windy area and is one of the top locations in the world for wind power, often considered to be the best in Europe. Since the 1980's, the number of wind farms has increased greatly. Wind turbines extract wind energy from 100 metres above the ground.

Airborne Wind Energy (AWE) systems enable the extraction of more energy from the wind at elevated altitudes beyond 150 meters using a technique termed pumping cycle kite power system. Scotland is the most suitable location for the implementation of AWE systems in the UK. In this work, the annual energy production of such a pumping cycle kite power system in Scotland was analysed using Luchsinger's analytical models. The annual energy production was found to be over $3.4 \mathrm{MWh} / \mathrm{m} 2$ in all five locations in Scotland.
\end{abstract}

Keywords: Airborne wind energy, pumping cycle kite power system

\section{Introduction}

Airborne Wind Energy (AWE) systems are an innovative technique to harvest wind energy at higher elevation, normally beyond $150 \mathrm{~m}$. AWE systems are expected to capture more wind energy and thus produce more electrical energy due to the higher and steadier wind speed at greater altitudes. AWE systems are generally made of two main components (i) a ground system and (ii) at least one aircraft that is mechanically or electrically connected by tethers. The AWE systems can be classified as Ground-Gen systems in which the conversion of mechanical energy into electrical energy takes place on the ground, and Fly-Gen systems in which such conversion is done on the aircraft [1]. In Ground-Gen Systems, electrical energy is produced by exploiting the mechanical energy transmitted from the aircraft to the ground through the tethers [2]. The Ground-Gen Systems can be classified further based on whether they have fixed or moving ground-stations. Ground-Gen Systems with fixed ground-stations, also known as pumping kite power systems, have been greatly developed by a number of companies and research groups during the last decade.

In the 1980s, the basic theoretical principle of AWE systems was introduced by the seminal work of Loyd [3] in which the maximum energy that can be theoretically extracted with AWE systems was analysed. Recently, the analytical models for a pumping cycle kite power system were presented by the work of Luchsinger [4] in which the influence of the tether's elevation angle on annual energy production was analysed.

Scotland is the most favourable location in the UK for the application of AWE systems [5]. However, the energy produced by the pumping kite power system has not been investigated. In the study, the analytical models for a pumping cycle kite power system [4] were used to analyse the annual energy

\footnotetext{
* Manuscript received Jan. 29, 2018; revised April 20, 2019.

Corresponding author. Tel.: +44 7871468482; E-mail address: yez4@1sbu.ac.uk.

doi: $10.12720 /$ sgce.8.4.377-382
} 
production for five locations in Scotland. Firstly, the analytical average mechanical power with known mean wind speeds were obtained by applying the models. Secondly, power production with the optimal elevation angle was calculated. Finally, the annual energy production was analysed. It was found that the annual energy production is up to $5.4 \mathrm{MWh} / \mathrm{m}^{2}$ Stornoway and over $3.4 \mathrm{MWh} / \mathrm{m}^{2}$ in all the other four locations in Scotland, UK. This is more than three folds higher than the energy that could be generated in the same areas per meter square using PVs [6].

\section{Working Principle of Pumping Cycle Kite Power Systems}

The design of the pumping cycle kite power system is one of the most basic forms of AWE system available. The pumping cycle kite power system utilises a kite connected by tether cables to a groundlevel station, which consists of cable reel drums fixed to generator motors, as shown in Fig. 1.

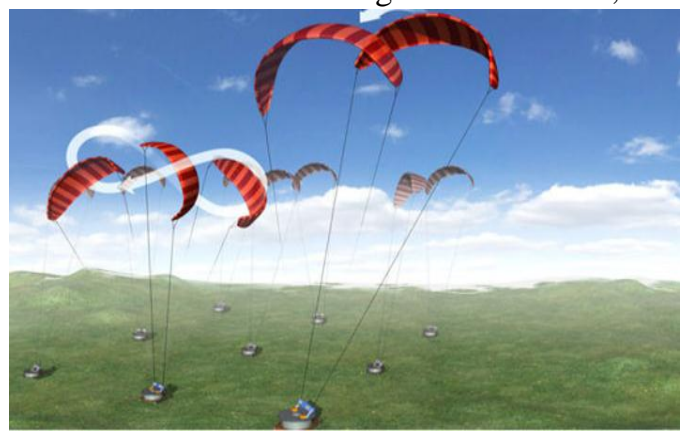

Fig. 1. Artist's rendering of a KiteGen prototype [7].

The idea of the pumping kite power system is to produce aerodynamic forces from a kite cutting across the wind, as it glides in a figure eight motion. The intense force created from the flying kite movements can stimulate a tug on the cable lines, producing energy as it rotates the reel drum connected to the generator, as shown in Figs. 2 and 3.

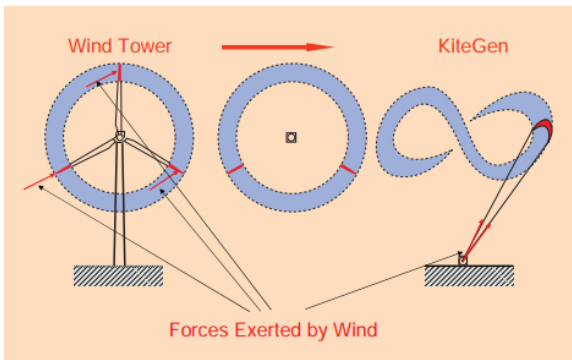

Fig. 2. Basic concept of KiteGen compared to wind turbine [8].

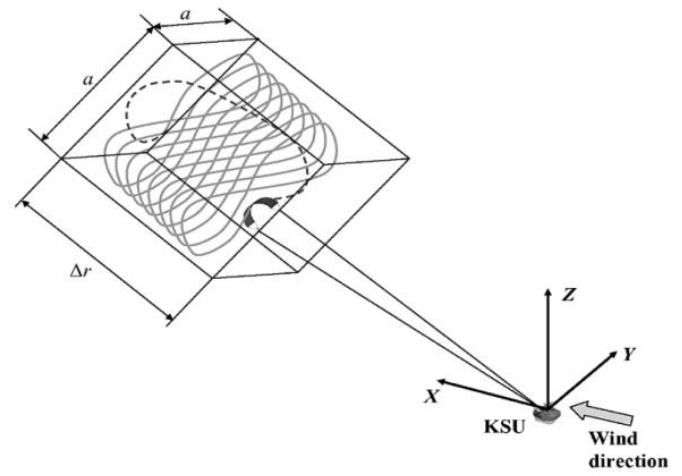

Fig. 3. The kite energy project yo-yo configuration cycle [9]. 
When the kite has extended to its peak altitude height, it performs a fall with low resistance enabling the cable drum to reel in the cable lines linked to the kite, and return to its original ideal starting height. The sequence then repeats itself, delivering a big gain in net power with every complete kite cycle. This is because of the power consumed in reeling back the kite is significantly less compared to the power produced $[9,10]$.

The energy conversion process takes place in the Kite Steering Unit (KSU), which consists of the electric drives, the drums and all the hardware used to control the movement of the kite. The movement of the kite produces forces, which are transmitted to the drums through the tethers. The drums are connected to electric drives or generators and these forces cause the drums to rotate, thereby producing electricity. The energy conversion mechanism is shown in Fig. 4.

\begin{tabular}{|c|c|c|c|c|}
\hline & Transmitted by tether & & Rotation of & \\
\hline Kinetic energy of wind captured & & Mechanical energy & generator & Electrical energy \\
\hline
\end{tabular}

Fig. 4 Energy conversion mechanism.

\section{Benefit and Drawback of Pumping Cycle Kite Power Systems}

A significant benefit of employing pumping cycle kite power systems is that the flight operating section of the system is extremely straightforward, and the kite trajectory allows the system to harvest and exploit a huge cross-sectional area of wind. Furthermore, as a result of the pumping cycle kite power systems being simple and unsophisticated, the materials implemented for the kites are bendable and soft. Therefore, the kite safety aspect of the system is enhanced, as in the event of system failure, there is no possible risk or hazard of a weighty rotor system falling from the sky.

In addition to the simplicity of the pumping cycle kite power systems, there could also be the added benefit of the capital costs being comparatively less expensive than traditional wind turbines and even fossil fuels [9]. The pumping cycle kite power system does not require a large expensive tower, which allows the system to be more economical and valuable to continue developing.

However, a drawback of this type of system is that the technique used in pumping cycle kite power systems has a lower aerodynamic efficiency for harvesting wind, in comparison to Fly-Gen systems. This is due to the pumping cycle kite power systems being unable to cope with turbulent wind speeds, which can cause knots and tangles to form in the tether lines. This is more likely to happen if several kites are flying together, connected in rows onto the same tether cables [11].

Furthermore, as energy is mechanically transferred to the ground from the pulling forces on the tether line, this suggests that the power generated is less when the tether line is drawn out longer. This is due to the increased mass of the line, combined with the greater force required to grasp higher wind speeds at high altitudes. This suggests that the pumping cycle kite power systems have a peak altitude for optimum performance, and it would appear that these systems perform best at lower altitudes, of up to roughly 1 $\mathrm{km}[9]$.

\section{Theoretical Analysis of Annual Energy Production by a Pumping Cycle Kite Power System}

The analytical models for a pumping cycle kite power system were developed by Rolf Luchsinger [4]. A strategy for evaluating the power generation for the pumping cycle kite systems is to divide the wind spectrum into two phases: (1) when wind speed $v_{w}$ is less than nominal wind speed $v_{n}$, i.e. $0 \leq v_{w} \leq v_{n}$ and (2) when nominal wind speed is less than wind speed, i.e. $v_{n} \leq v_{w}$.

The average annual power $P_{a v}(\mathrm{~W})$ of the pumping cycle kite power systems can be calculated as [4]

$$
P_{a v}=\int_{0}^{v_{n}} P_{w} A F_{o u t} f_{c} g w\left(v_{w}\right) d v_{w}+\int_{v_{n}}^{v_{c} u t} P_{w} A F_{o u t} f_{c, \mu} g w\left(v_{w}\right) d v_{w}
$$


where $P_{w}$ is the power density $\left(\mathrm{W} / \mathrm{m}^{2}\right)$, A is the kite wing area $\left(\mathrm{m}^{2}\right), F_{\text {out }}$ is the dimensionless force factor when the kite is reel out, $f_{c}$ is the power factor for one cycle, $f_{c, \mu}$ is the power factor for one cycle when $v_{w}=v_{n}, g w\left(v_{w}\right)$ is the Weibull probability density, $v_{n}$ is nominal wind speed $(\mathrm{m} / \mathrm{s}), v_{c u t}$ is the cut-out wind speed $(\mathrm{m} / \mathrm{s})$. For $v_{w}>v_{\text {cut }}$ power production ceases.

For ratio of dimensionless force factors $F_{\text {out }} / F_{i n}=10, v_{n}=10 \mathrm{~m} / \mathrm{s}, v_{\text {cut }}=25 \mathrm{~m} / \mathrm{s}$, and shape factor $k=1.5$ for the Weibull probability density function, the average mechanical power as a function of the average wind speed is given in Fig. 5 [4].

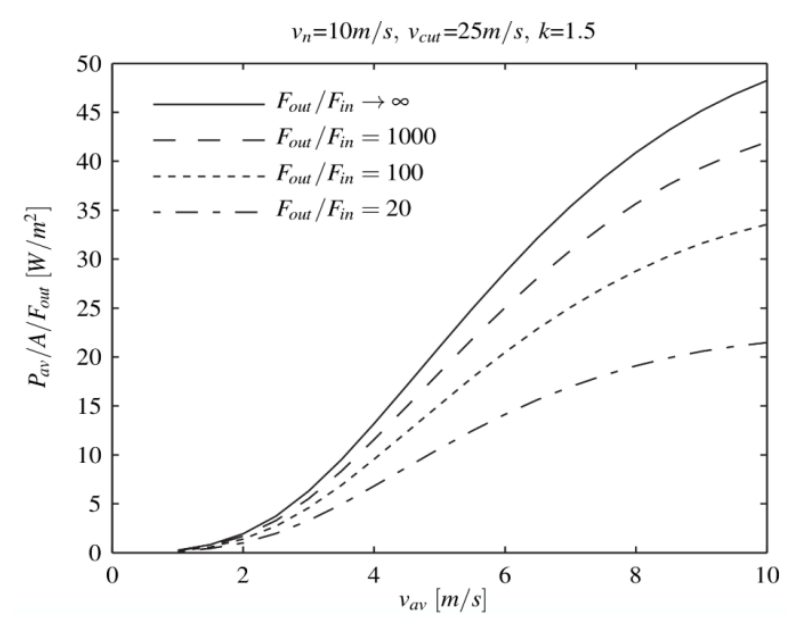

Fig. 5. Average mechanical power as a function of the average wind speed [4].

The annual mechanical energy $E_{y}(\mathrm{Wh})$ produced by the power system is calculated as [4]

$$
E_{y}=8760 P_{a v}
$$

The mechanical power and energy produced by the pumping cycle kite system calculated above assumes that the tether is parallel with the direction of the wind. In reality, this is not practical because the tether is anchored on the ground but the kite flies at some altitude above ground. The power production of the kite power system is greatly influenced by the elevation angle $\theta$ of the tether with the horizontal wind direction. Numerical simulation shows that for $\theta \leq 45^{\circ}$ the mechanical power is calculated as [4]

$$
P_{a v}^{\theta}=P_{a v}^{\theta=0} \cos ^{3} \theta
$$

Equation (3) verifies that $\theta$ strongly influences the power production of the pumping kite cycle power system. In practice, it was suggested that $\theta=30^{\circ}$ is a good compromise of the wind speed and tether length for reasonable power production [4].

\section{Power Production Calculation by Applying the Analytical Models}

Applying Fig. 5 with known mean wind speed, $P_{a v} / A / F_{\text {out }}$ can be read out. Multiplying by a proposed $F_{\text {out }}$, the average mechanical power per unit area $\left(P_{a v} / A\right)$ for $\theta=0^{\circ}$ can be calculated. Considering the elevation angle $\theta$ and using Equation (3), the average mechanical power per unit area $\left(P_{a v} / A\right.$ ) can be obtained. Using Equation (2), the annual mechanical energy produced by a pumping kite 
power system is obtained.

For $F_{\text {out }} / F_{i n}=10$ with an average wind speed of $8 \mathrm{~m} / \mathrm{s}, P_{a v} / A / F_{o u t}=28.8 \mathrm{~W} / \mathrm{m}^{2}$ can be read out. For $F_{\text {out }}=50$, the average mechanical power is $1.4 \mathrm{~kW} / \mathrm{m}^{2}$ for a pumping kite power system [4]. For $\theta=3 \odot^{\circ}$, the average mechanical power is $0.91 \mathrm{~kW} / \mathrm{m}^{2}$. The product of the average mechanical power and the number of hours $(8760 \mathrm{~h})$ is the annual energy production, $7972 \mathrm{kWh} / \mathrm{m}^{2}$.

\section{Results of Power Production Calculation}

In the UK, Scotland is the best location to implement the AWE system [5]. A higher cycle power can be obtained with a greater tether force. In this study, $F_{\text {out }} / F_{i n}=10$ and $F_{\text {out }}=50$ were used [4]. $\theta=30^{\circ}$ has been taken as an approximation for the optimal elevation angle. The mass of the kite was ignored. The annual energy production of such a pumping kite power system at five locations in the Scotland were calculated and are shown in Table 1. The wind data was taken from CIBSE Guide J [12].

Table 1. Annual energy production by a pumping cycle kite power system

\begin{tabular}{|c|c|c|c|c|c|c|}
\hline Location & $V_{a v}$ & $P_{a v} / A / F_{\text {out }}$ & $\Theta$ & $F_{\text {out }}$ & $P_{a v}$ & $E_{y}$ \\
\hline & $(\mathrm{m} / \mathrm{s})$ & $\left(\mathrm{W} / \mathrm{m}^{2}\right)$ & & $\left(\mathrm{W} / \mathrm{m}^{2}\right)$ & $\left(\mathrm{kWh} / \mathrm{m}^{2}\right)$ \\
\hline Aberdeen & 4.50 & 12.5 & 30 & 50 & 406 & 3556 \\
\hline Edinburgh & 4.45 & 12.0 & 30 & 50 & 390 & 3414 \\
\hline Glasgow & 4.39 & 11.8 & 30 & 50 & 383 & 3357 \\
\hline Leuchars & 4.97 & 15.0 & 30 & 50 & 487 & 4267 \\
\hline Stornoway & 5.67 & 19.0 & 30 & 50 & 617 & 5405 \\
\hline
\end{tabular}

\section{Conclusions}

The UK is a prime geographical location, considered to be the best in Europe, for harvesting wind energy, and over the last three decades, the number of wind farms has increased greatly. This study has looked at the feasibility of implementing pumping cycle kite power systems in the UK. The benefits and drawbacks of pumping cycle kite power systems have been investigated in this study. In addition, the potential annual energy production from a pumping cycle kite power system has been calculated for five locations in Scotland, UK. This was done using Luchsinger's analytical models and considering CIBSE weather data for the five studied locations in Scotland, UK. The results have revealed a potential annual energy production of upto $5.4 \mathrm{MWh} / \mathrm{m}^{2}$ at Stornoway, $4.3 \mathrm{MWh} / \mathrm{m}^{2}$ at Leuchars and between 3.3 and 3.6 $\mathrm{MWh} / \mathrm{m}^{2}$ for the other locations considered in this study. This is on average more than three folds higher than the energy that could be collected from PVs per meter squarer in the same regions.

This outcome suggested that within the Scottish region, the pumping cycle kite power system is an innovative renewable energy technique that yields more energy than conventional wind turbines.

\section{Acknowledgements}

The authors gratefully acknowledge the financial support of the Center for Civil and Building Services Engineering (CCiBSE) at London South Bank University.

\section{References}

[1] Diehl M. Airborne wind energy: basic concepts and physical foundations. In: Ahrens U, Diehl M, Schmehl R, editors. Airborne wind energy, Berlin: Springer; 2013:3-22 [Chapter 1].

[2] Cherubini A, Papini A, Vertechy R, Fontana M. Airborne wind energy systems: a review of the technologies. Renewable and Sustainable Energy Reviews, 2015; 51:1461-1476.

[3] Loyd M. Cross wind kite power (for large-scale wind power production). Journal of Energy, 1980; 4(3):106-111.

[4] Luchsinger R. Pumping cycle kite power. In: Ahrens U, Diehl M, Schmehl R, editors. Airborne wind energy, Berlin: Springer; 
2013:47-64 [Chapter 3].

[5] Ye Z, Lawner H, Chaer I, Ross M. Viability of airborne wind energy in the United Kingdom. Presented at: 2018 Eleven International Conference on Thermal Engineering: Theory and Applications.

[6] BlueBuildEnergy. (2018). Solar radiation UK map for solar panels. [online]. Available: http://www.bluebuildinsulation.com/store.

[7] Torino Today. (2015). KiteGen: the kite invented in Turin that produces energy from the wind. [Online]. Available: http://www.torinotoday.it/green/energia/kitegen-aquilone-energia-vento.html

[8] Hoffert M, Caldeira K, Jain A, Haites E, Harvey L. Energy implications of future stabilization of atmospheric $\mathrm{CO}_{2}$ content. Nature, 1998; 395:881-884.

[9] Fagiano L, Milanese M, Piga D. High-altitude wind power generation. Control Systems Technology: IEEE Transactions on Energy Conversation, 2010; 18(2):168-180.

[10] Canale M, Fagiano L, Milanese M. Power kites for wind energy generation: fast predictive control of tethered airfoils. $U K$ : IEEE Control Systems Magazine, 2007.

[11] Houska B. Robustness and stability otimiziation of open-loop controlled power generating kites. Germany: University of Heidelberg; 2007.

[12] CIBSE, Weather, Solar and Illuminance Data: Guide J, The Chartered Institution of Building Services Engineers London; 2002. 